\title{
National and subnational Red Lists in European and Mediterranean countries: current state and use for conservation
}

\author{
Claire-Sophie Azam ${ }^{1, *}$, Guillaume Gigot ${ }^{1}$, Isabelle Witte ${ }^{1}$, Bertrand Schatz ${ }^{2}$ \\ ${ }^{1}$ SPN (Service du Patrimoine Naturel), Muséum National d'Histoire Naturelle, CP 41, 36 rue Geoffroy Saint-Hilaire, \\ 75005 Paris, France \\ ${ }^{2}$ CEFE (Centre d'Ecologie Fonctionnelle et Evolutive), UMR 5175, \\ CNRS - Université de Montpellier - Université Paul-Valéry Montpellier - EPHE - 1919 route de Mende, 34293 Montpellier, \\ France
}

\begin{abstract}
In the context of ongoing biodiversity loss and limited resources allocated to nature conservation, operational tools to prioritize and implement relevant conservation actions are crucial. The IUCN Red List of Threatened Species (RLTS) is recognized as the most comprehensive tool for assessing risk of species extinction, based on a standardized methodology that is applicable for most taxa and geographic regions. Now established at regional, national and subnational scales, Red Lists have grown rapidly and autonomously thanks to active local initiatives. We investigated national and subnational Red Lists in 53 European and Mediterranean countries to get an overview of their ongoing development and uses in this region in 2014. Through an online questionnaire, we identified national Red Lists in 41 countries and subnational Red Lists in 16 countries. The public sector is the main coordinator and funder of RLTSs, while the IUCN has a limited involvement in local initiatives. Availability of data and expertise are the main factors determining the choice of taxonomic groups to be assessed. Red Lists, notably national ones, are widely used in national conservation initiatives, mainly to prioritize species and sites. However, there are taxonomic and geographic coverage gaps and increased investment is needed to train experts and improve data quantity and quality. A worldwide strategy for development of regional RLTSs needs to be drawn up, along with the strengthening of a network of producers and users to increase their potential to contribute to biodiversity conservation.
\end{abstract}

KEY WORDS: National Red List - Subnational Red List - Threatened species · Conservation programs $\cdot$ Europe $\cdot$ Mediterranean region $\cdot$ Survey $\cdot$ IUCN

\section{INTRODUCTION}

Biodiversity loss is occurring at a rapid pace, and scientific evidence suggests we might be facing a sixth mass extinction (Butchart et al. 2010, Barnosky et al. 2011). In response to this crisis, the Convention on Biological Diversity (CBD) established as a main target to 'achieve a significant reduction of the current rate of biodiversity loss at global, national and regional

*Corresponding author: azam.clairesophie@gmail.com levels' by 2010 (UNEP 2014). This target was not met (Butchart et al. 2010), and ongoing changes in biodiversity and its dynamics are a growing concern for society (Pereira et al. 2010, Carvalheiro et al. 2013). As a consequence, the Parties of the CBD have agreed to a new strategic plan to prevent the extinction and improve the conservation status of threatened species by 2020 (CBD 2014). To achieve this objective, National Red Lists of Threatened Species (NRLTS) have been

() The authors 2016. Open Access under Creative Commons by Attribution Licence. Use, distribution and reproduction are unrestricted. Authors and original publication must be credited.

Publisher: Inter-Research · www.int-res.com 
identified as a major indicator to monitor progress toward biodiversity targets (Zamin et al. 2010).

The IUCN Red List of Threatened Species (RLTS) is the most comprehensive source of information on species conservation status and threats (Lamoreux et al. 2003, De Grammont \& Cuarón 2006, Mace et al. 2008 , IUCN 2014b). It is used to inform the general public on species' conservation status, monitor the state of biodiversity, advise policies and programs, identify priority sites and species for conservation and orient scientific research (Rodrigues et al. 2006, IUCN 2011). The standardized methodology elaborated by the IUCN in 1994 and updated in 2001 allows the classification of species into 9 threat categories (IUCN 2012a, 2014a). The species classified in the Vulnerable (VU), Endangered (EN) and Critically Endangered (CR) categories are considered 'threatened.' Originally defined for use at the global scale (Mace \& Lande 1991, IUCN 1994, 2001, 2012a), guidelines were produced to apply RLTS categories and criteria at the regional scale (Gärdenfors 2001, IUCN 2003, 2012b). Over the last decade, a growing set of RLTS has thus been established at regional, national and subnational scales to allow a better knowledge of local status of biodiversity conservation (Rodríguez 2008, Collen et al. 2013). The spontaneous development of national and subnational Red Lists of Threatened Species (NRLTSs and SRLTSs), emerging from local initiatives, quickly drifted away from the IUCN's coordination, leading to a divergence of standards for red listing. Therefore, the IUCN Species Survival Commission (SSC) National Red List Working Group established the National Red List Alliance (NRLA) to promote the NRLTS process globally. They implemented a website (National Red List 2014) aimed at gathering information on NRLTS assessments but, to this date, a complete list of NRLTSs in the Euro-Mediterranean region is not available.

On the other hand, several valuable studies have given an overview of the development of NRLTSs over the past decade (Köppel et al. 2003, Miller et al. 2007, Zamin et al. 2010). They show unequal geographic coverage of NRLTSs and that regions with the most important stakes for biodiversity have developed fewer NRLTSs (McKinney 1999, Zamin et al. 2010). Several methodological questions have also been raised, especially regarding the applicability of IUCN methodology to less well-known areas and taxa (Miller et al. 2007). Despite published recommendations (Miller et al. 2007, Rodríguez 2008), several points of confusion persist in the use of RLTSs (e.g. RLTSs used directly as a list of protected species or as a template to establish conservation priorities), which hampers both the production and use of RLTSs for conservation (Possingham et al. 2002, Farrier et al. 2007, Martín-López et al. 2011).

Conservation programs and policies in Euro-Mediterranean countries are framed by international and community commitments such as Birds and Habitats Directives (Council of the European Commission, 1992, 2009) and the CBD (UNEP 2014, Cog lniceanu \& Cog lniceanu 2010, Henle et al. 2013). The Mediterranean region, identified as a hotspot of biodiversity, is also one of the most threatened areas in the world (Myers et al. 2000, Cuttelod et al. 2009, Blondel et al. 2010). In this context, it is expected that species status assessments should feature prominently in conservation strategies but, so far, little information exists on the contribution of RLTSs to national programs. Information available on NRLTSs in EuroMediterranean countries is limited and the use of NRLTSs for conservation programs and policies has not previously been surveyed.

For the 50th anniversary of the IUCN RLTS, we investigated NRLTSs and SRLTSs in Euro-Mediterranean countries. Our study provides a regional overview of the state of development of RLTSs and their uses in national conservation strategies. Our aim was to identify trends in the development of NRLTSs and SRLTSs and assess their scope for conservation in this region.

\section{METHODS}

\section{Online survey}

We developed a questionnaire to obtain information on RLTS production, national conservation programs/policies and the use of RLTSs in those programs (see Supplement 1 at www.int-res.com/articles/ suppl/n030p255_supp.pdf). We adopted several typologies to describe stakeholders, RLTS methodologies, taxonomic groups (19 groups selected), the determining factors for the development of RLTSs, conservation programs/policies, and uses of RLTSs. The questionnaire included 398 conditional questions (questions to be answered depending on the previous answer). It included closed and open questions, mandatory and non-mandatory questions as well as simple and multiple choice questions. In this last case, the sum of percentage in the results can be more than $100 \%$. We built the online questionnaire (English/French) using the open source software LimeSurvey ${ }^{\circledR}$ (LimeSurvey 2011) (Supplement 1). 
Data are unavailable for the Republic of Macedonia with respect to the use of Red Lists in national conservation policies and programs.

\section{Participants in the questionnaire}

The study area included 53 countries from Europe and around the Mediterranean basin. Invitations to participate in the online questionnaire were sent to 351 persons identified as working with RLTSs and national conservation strategies. Respondents were from public bodies, research institutions, NGOs and other civil society organizations, with an average of 6 persons per country (range: 2 to 19). The questionnaire ran for 6 wk from May to June 2014 (see Supplement 1 for more information).

\section{Selection and grading of replies}

Several individuals from each country may have answered the same question. According to a standardized protocol (Supplement 2 at www.int-res. com/articles/suppl/n030p255_supp.pdf), a synthesis of answers for each country was made and graded according to a level of confidence, from A (good) to C (low) based on the consistency, justification and documentation of the answers. Nine experts involved in international conservation initiatives were interviewed to confirm and/or complete the results. NRLTSs and SRLTSs can be elaborated according to different methodologies, at different periods of time and under different formats (RLTS or Red Data Book); all variants were included in the present study. A Red Data Book generally gathers information focusing on the most threatened and rare species and their conservation measures, while a RLTS aims at compiling risk assessments and associated data for an entire taxonomic group.

\section{Primary classification of countries}

We divided the countries into 3 groups depending on the sizes of their administrative regions: 'smallregions countries' ( $\mathrm{n}=18$, sizes of administrative regions ranging from 2 to $3120 \mathrm{~km}^{2}$ ), 'medium-regions countries' ( $\mathrm{n}=18$, size range: 3121 to $15106 \mathrm{~km}^{2}$ ) and 'large-regions countries' ( $\mathrm{n}=17$, size range: 15107 to $75346 \mathrm{~km}^{2}$ ) (GADM 2014). We also selected 14 significant descriptive variables (geographic, cultural and socio-economic) to characterize countries (Sup- plement 3 at www.int-res.com/articles/suppl/n030 p255_supp.pdf).

\section{Description of results}

The results are presented as percentages based on replies on closed questions, and exclude 'don't know' answers. Open questions are used for the interpretation and referred to in the 'Discussion'. Data are unavailable for the Republic of Macedonia for the second part of the questionnaire, i.e. the section concerning the uses of Red Lists in national conservation policies and programs.

\section{Multivariate analysis}

A principal component analysis (PCA) was performed to identify RLTS production strategies among countries. We also conducted a redundancy analysis (RDA) (see Supplement 3) to observe the relationships between conservation strategies and variables describing the countries. Kosovo, Belarus and Moldova were not included in this analysis, due to missing data in the survey results for these countries.

\section{RESULTS}

\section{The survey}

We received 322 questionnaires with answers (92\% of invitations) and selected the 134 most complete ones (1 to 6 per country). Most respondents (83\%) were from the public sector and research institutes. We had good confidence (A) in $45 \%$ of the answers per country and only $18 \%$ were deemed to present a low rate of confidence (C) (Supplement 2).

\section{Current state of NRLTSs and SRLTSs in the Euro-Mediterranean region}

Among the 53 countries surveyed, 41 had developed NRLTSs (Fig. 1), 8 planned to do so and 3 did not plan to develop one, mostly for operational reasons (lack of expertise/data availability). Twenty-two countries (54\% of the countries with NRLTSs) had reassessed their NRLTS and 9 of them (22\%) had compiled a Red List Index (RLI) (Butchart et al. 2005). SRLTSs were identified in 16 countries and 3 planned 


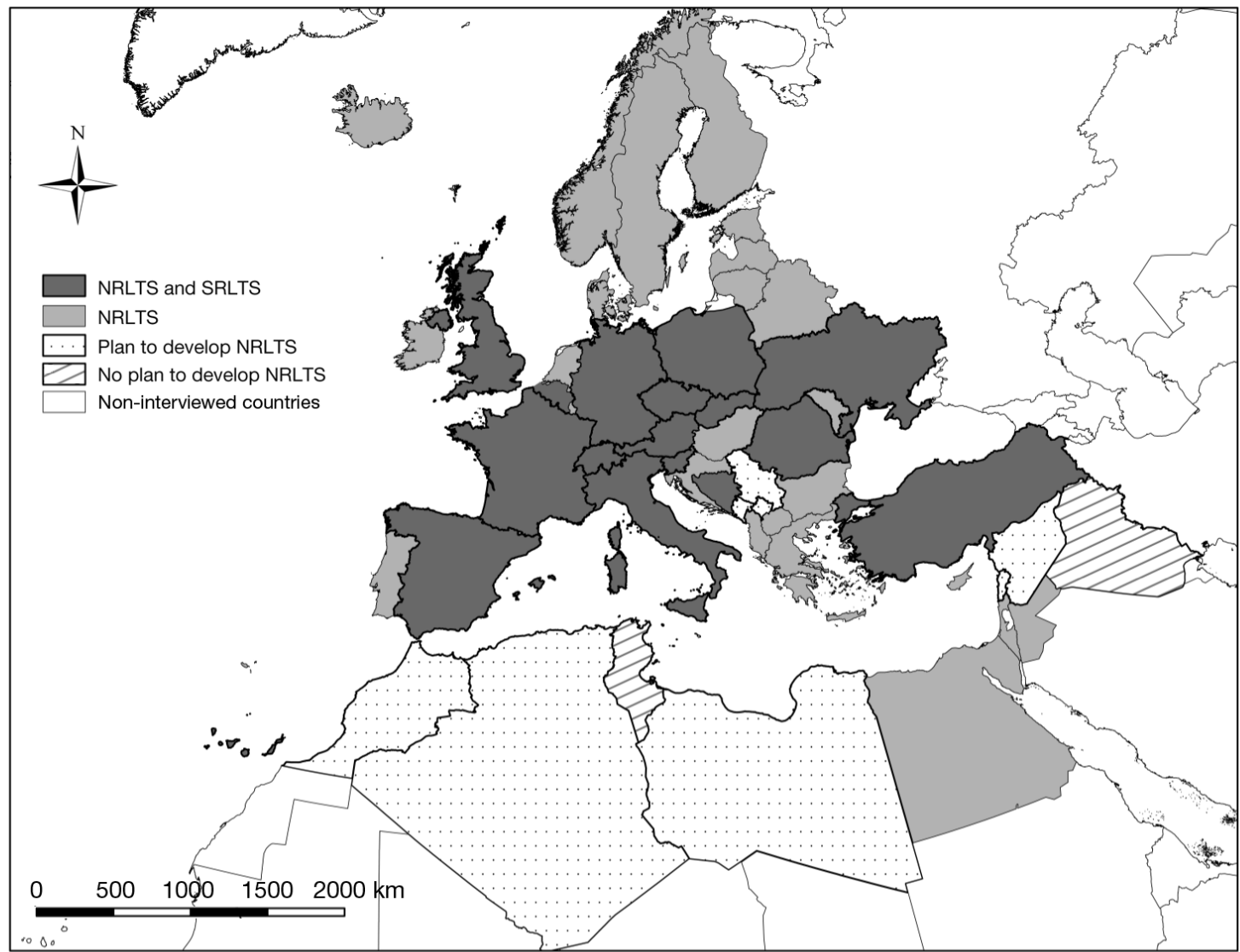

Fig. 1. Distribution of national (NRLTS) and subnational Red Lists (SRLTS) in Euro-Mediterranean countries in 2014. Map created with ARCGIS 10.2.2 (ARCGIS 2014)

to develop some within a few years. $53 \%$ of the countries without SRLTS stated that their administrative regions were too small for SRLTS assessments. SRLTSs were reassessed in 8 countries and RLIs based on SRLTS had been compiled in 5 countries ( $31 \%$ ).

\section{RLTS production stakeholders}

NRLTSs and SRLTSs are mainly coordinated by the public sector $(87 \%$ of the countries for NRLTSs and $81 \%$ for SRLTSs) and research institutes (primarily universities and natural history museums) (54\% for NRLTSs, 38\% for SRLTSs) followed by NGOs (29\% for NRLTSs, $19 \%$ for SRLTSs) and managers of protected areas (10\% for NRLTSs, $13 \%$ for SRLTSs). As the data makes clear, RLTSs can be coordinated by more than one organization in each country. The IUCN national committees have a moderate role in NRLTS coordination and, as of 2014, only the French and Italian national committees had a significant role in it. None of the respondents identified a private sector organization as coordinator of a NRLTS or
SRLTS. Respondents highlighted the prominent role of experts in leading RLTS initiatives. They contribute largely on a voluntary basis, in $43 \%$ of cases for NRLTSs and $63 \%$ for SRLTSs, and in some cases personally fund the production of an RLTS. The public sector is the main funder of RLTSs $(95 \%$ of the countries for NRLTSs and $88 \%$ for SRLTSs) while the private sector makes a limited contribution (to $22 \%$ NRLTSs, $25 \%$ for SRLTSs); note again that RLTSs can be funded by more than one organization in each country. Nevertheless, private funding seems to be more important for SRLTSs than for NRLTSs: respondents from $19 \%$ of the countries stated that privates organizations has a 'strong' participation in SRLTSs versus $5 \%$ for NRLTSs.

\section{RLTS methodologies}

NRLTSs were mostly elaborated following the 2001 IUCN methodology (IUCN 2001): 20 out of 41 countries $(49 \%$ of countries with NRLTSs) adopted the IUCN methodology, while 16 countries (39\%) used 


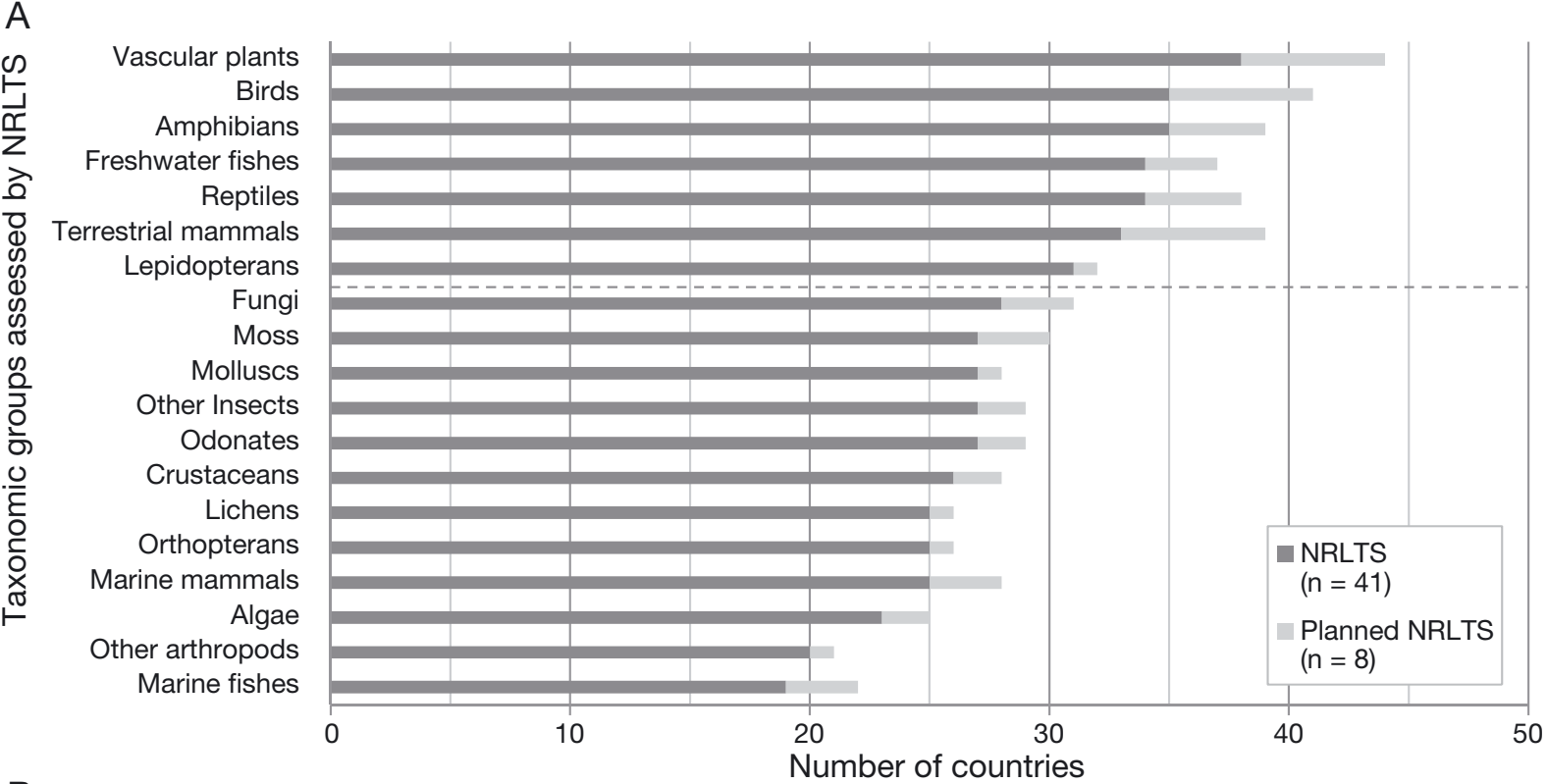

B
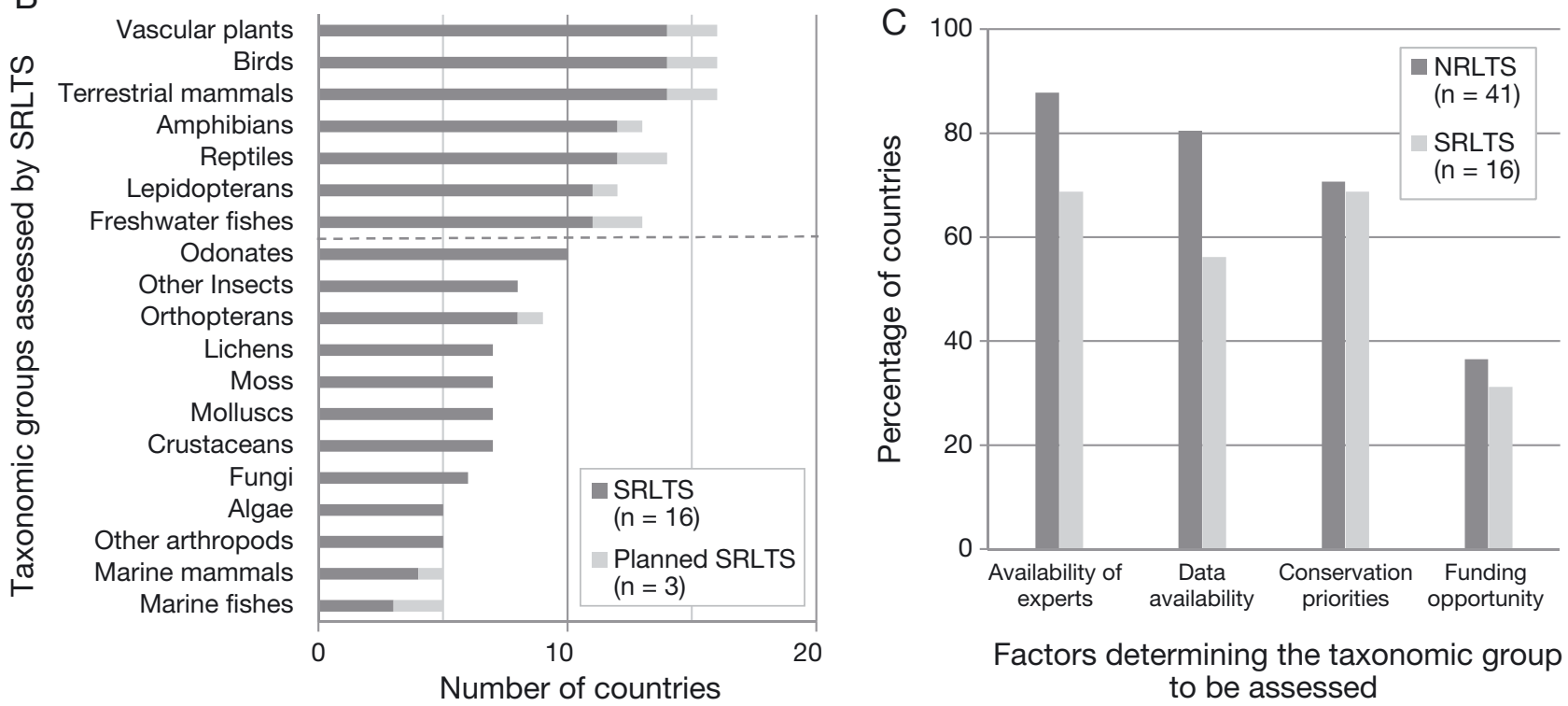

Factors determining the taxonomic group to be assessed

Fig. 2. Current and planned assessment of taxonomic groups assessed by (A) national Red Lists (NRLTS) and (B) subnational Red Lists (SRLTS) in Euro-Mediterranean countries. The dashed lines separate well assessed groups from less well assessed groups. (C) Factors determining the choice of taxonomic groups to be assessed by NRLTS and SRLTS, shown as the percentage of the countries that have developed NRLTS and/or SRLTS

a methodology adapted from the IUCN categories and criteria. Three countries $(7 \%)$ used their own methodology and the superseded 1994 IUCN methodology (IUCN 1994) was used in 2 countries (5\%). For SRLTSs, 10 out of 16 countries (63\% of SRLTS countries) used their own methodologies, mostly based on the IUCN methodology. The 2001 IUCN methodology was used for SRLTS in 5 countries (31\%) and the 1994 IUCN methodology in 3 countries $(19 \%)$; note that more than one methodology can be used among the different subnational regions of a country. In re- sponses to the open questions, respondents underlined the lack of coordination among SRLTS producers within a country and the difficulties involved in using SRLTSs developed from different methodologies.

\section{Choice of taxonomic groups assessed by RLTSs}

Fig. 2 shows the coverage of the 19 taxonomic groups selected by NRLTSs and SRLTSs. As expected, the most emblematic and well-known groups (vascular 


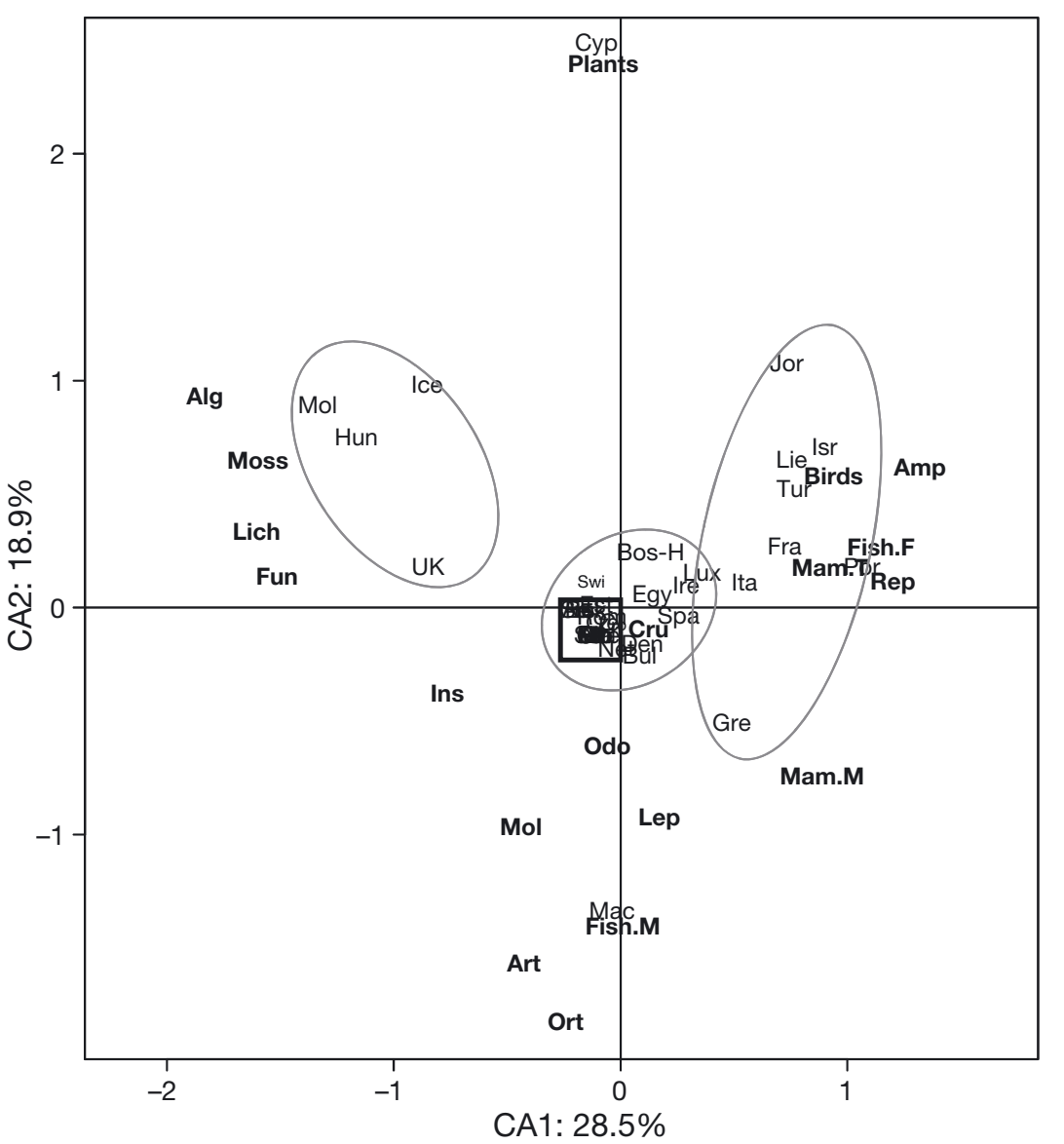

Fig. 3. Principal component analysis of coverage of taxa in national Red Lists of countries in the Euro-Mediterranean region. Ovals outline groups of countries that evaluated a broad range of taxonomic groups (center), focused on well-known groups (right), and were motivated by less well-known groups (left).

Country abbreviations. Bos-H: Bosnia and Herzegovina, Bul: Bulgaria, Cyp: Cyprus, Dan: Denmark, Egy: Egypt, Fra: France, Gre: Greece, Hun: Hungary, Ice: Iceland, Ire: Ireland, Isr: Israel, Ita: Italy, Jor: Jordan, Lie: Liechtenstein, Lux: Luxembourg, Mac: Macedonia, Mol: Moldova, Por: Portugal, Spa: Spain, Swi: Switzerland, Tur: Turkey, UK: United Kingdom. The black box in the center of the diagram contains the following countries: Albania, Austria, Belarus, Croatia, Czech Republic, Estonia, Finland, Germany, Latvia, Lithuania, Malta, The Netherlands. Norway, Poland, Romania, Slovakia, Slovenia, Sweden and Ukraine.

Taxonomic groups (in bold). Alg: algae, Amp: amphibians, Art: other arthropods, Birds: birds, Bryo: bryophytes, Cru: crustaceans, Fish.F: freshwater fishes, Fish.M: marine fishes, Fun: fungi, Ins: other insects, Lep: lepidopterans, Lich: lichens, Mam.M: marine mammals, Mam.T: terrestrial mammals, Mol: molluscs, Moss: mosses, Odo: odonates, Ort: orthopterans, Plants: vascular plants, Rep: reptiles plants, vertebrates, Lepidoptera) were assessed more frequently than less well-known groups (fungi, most invertebrates, non-vascular plants, marine fishes). The 7 most assessed groups were the same for NRLTSs and SRLTSs ( $>30$ and $>10$ countries respectively) and were also more frequently targeted for future RLTS assessments. The choice of taxonomic group to be assessed was influenced by expert availability (88\% of the countries for NRLTSs and $69 \%$ for SRLTSs), data availability ( $80 \%$ for NRLTSs, $56 \%$ for SRLTSs), conservation priorities (71\% for NRLTSs, $69 \%$ for SRLTSs) and, more rarely, funding opportunities (37\% for NRLTSs, 31\% for SRLTSs; based on responses to a multiple choice question).

A PCA analysis (Fig. 3) investigated interactions between traits of countries and the choice of taxonomic groups to be assessed by NRLTSs. Three distinct groups of countries emerged: (1) countries that evaluated a broad range of taxonomic groups; (2) countries focused on well-known groups; and (3) countries motivated by an interest in less well-known groups. This analysis identified a separation between the level of knowledge of taxa on the horizontal axis and the type of assessment on the vertical axis
(Fig. 3). Within countries focusing on less wellknown taxa, 75\% used a methodology adapted from the IUCN methodology, while $75 \%$ of countries focusing on well-known taxa used the 2001 IUCN methodology in its original form.

\section{Biodiversity conservation strategies}

Among the respondents from 52 countries that answered this part of the questionnaire, the most frequent programs/policies adopted were national lists of protected species ( $98 \%$ of the countries surveyed), national strategies for biodiversity $(90 \%)$, programs of work on protected areas $(85 \%)$, inventories of areas of biodiversity interest $(85 \%)$ and national action plans (NAP) (83\%) (Fig. 4). However, according to the commentaries, many of those programs are obsolete and/or have not been implemented. Thus, the apparent uniformity in national conservation strategies hides strong differences in the implementation of initiatives. Non-mandatory and small-scale initiatives were notably scarcer; these included biodiversity monitoring centers (50\% of the countries), 


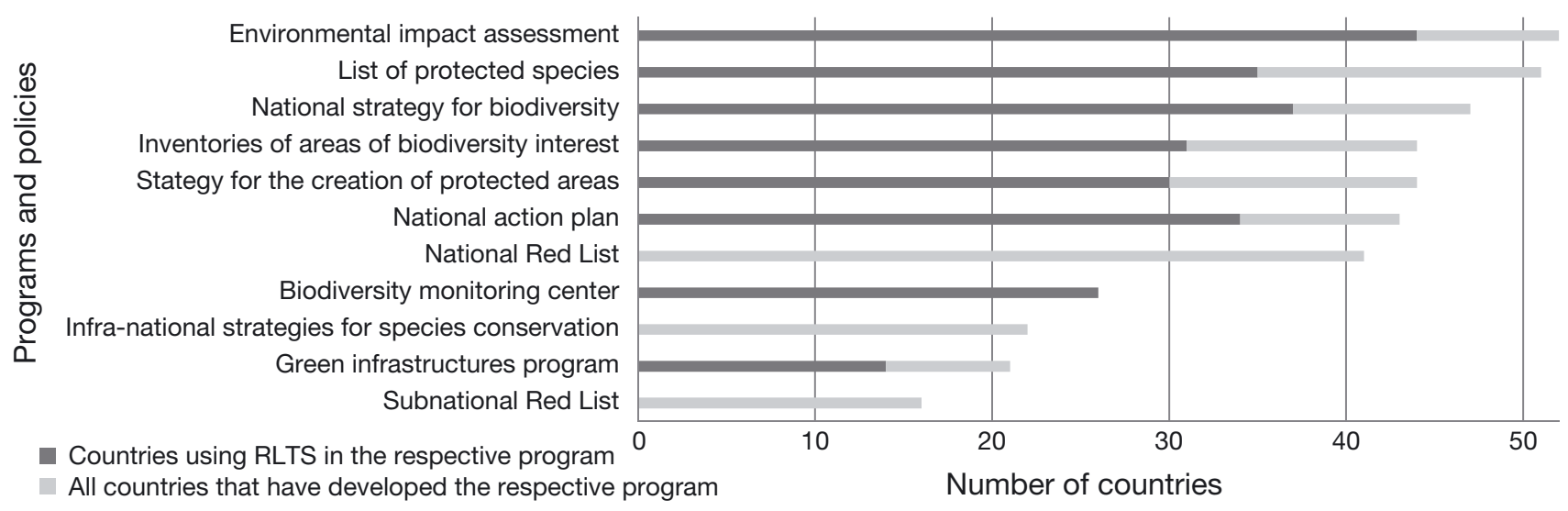

Fig. 4. Use of Red Lists (RLTS) in national conservation programs and policies, showing the number of Euro-Mediterranean countries $(n=52)$ that have developed each program (black bars) and the number that used national and/or subnational Red Lists in developing and/or implementing the program (grey bars). Note that data are not available for uses of RLTS in subnational strategies for species conservation

subnational strategies for conservation $(42 \%)$ and green infrastructure programs $(40 \%)$.

The mean size of the administrative regions of a country appeared to be a key factor in the development of subnational conservation strategies and SRLTSs. Such strategies were developed in $23 \%$ of the small-regions countries, $39 \%$ of medium-regions countries and $65 \%$ of large-regions countries. Within the 22 countries which had developed subnational strategies, $59 \%$ had also developed SRLTSs.

In order to understand the factors that shaped biodiversity conservation strategies in the studied region, we conducted an RDA to compare the existing programs and policies with the variables describing the countries. We found a 'north-south' divide where countries from Europe and with high socio-economic stability (based on the country risk assessment indicator developed by COFACE insurance company; Coface 2014) developed more programs than Mediterranean countries with low socio-economic stability. Countries with a temperate climate and a high level of endemism were more involved in NRLTS and SRLTS production than countries from the desert ecoregion (Fig. 3, Supplement 3).

\section{Uses of RLTSs in biodiversity conservation initiatives}

RLTSs were used by all biodiversity monitoring centers $(100 \%)$ and in 67 to $85 \%$ of the cases to support other programs (Fig. 4, Supplement 4 at www. int-res.com/articles/suppl/n030p255_supp.pdf). When asked to classify which RLTS was preferentially used for conservation, NRLTSs were by far the most widely used, followed by supra-national RLTSs (Mediterranean, European etc.) and then the global RLTS. The exceptions were NAPs and ecological impact assessments (EIAs) for which the global RLTS was the second most commonly used type of RLTS. SRLTSs were mainly used for small-scale initiatives, such as EIAs, green infrastructure programs and inventories of areas of biodiversity interest.

RLTSs were used mainly as a prioritization tool to select species or sites for conservation. On average, $87 \%$ of the countries that used RLTSs in the programs listed in the questionnaire (data unavailable for EIAs and biodiversity monitoring centers) declared a 'strong/medium' use of RLTSs for prioritization of species. We also identified 23 countries that had a recognized prioritization methodology, of which $83 \%$ cited RLTSs as the basis of the methodology. With respect to other uses, $81 \%$ of the countries used RLTSs for information and communication, $80 \%$ to advise policies and programs, $76 \%$ to monitor biodiversity status, and $70 \%$ to orient research priorities.

\section{DISCUSSION}

NRLTSs and SRLTSs have been successfully implemented in the European region thanks to a continuing mobilization of local stakeholders. Nevertheless, the general overview provided by our results reveals several limiting factors in this autonomous RLTS development: availability of data and/or experts, applicability of the methodology to some taxonomic groups or unknown areas, lack of coordination. 


\section{Nature of NRLTSs and SRLTSs}

Defining an RLTS is a complex process as such a list can assess different areas (regional, national, subnational), include one or several chapters, assess an entire taxonomic group or just selected species, be published at different times from an RLTS or Red Data Book, and be elaborated according to different guidelines (Köppel et al. 2003, Miller et al. 2007). NRLTSs can have different objectives and uses depending on their implementation process (Burton 2003). For example, Germany, which is a driving actor in the development of NRLTSs, has assessed most taxonomic groups and uses the country's own RLTS methodology (BFN 2014). This methodology aims to assess whether or not a species can fulfill its role in nature, in contrast to IUCN methodology which focuses entirely on the risk of extinction. There are thus a range of different ways in which an RLTS can be produced and used.

\section{RLTS development in the Euro-Mediterranean region}

This review reveals a continuing development of NRLTSs and SRLTSs (in all their forms) in the region, driven by national public bodies. NRLTSs are mainly elaborated following the IUCN methodology, while SRLTSs are more frequently compiled using adapted methodologies. Indeed, SRLTSs are generally produced in response to specific needs, in an autonomous way and without national support. Differences among methodologies do not seem to inhibit their development. Nevertheless, respondents stated that it was difficult to combine SRLTSs produced using different methodologies for cross-scale conservation programs. They also expressed a desire for their tools to be more widely acknowledged and accorded greater credibility. This study shows a strong interest of local stakeholders in SRLTSs but, so far, the IUCN has not paid much attention to these emerging initiatives. However, SRLTSs, just as Rodríguez suggested for NRLTSs (Rodríguez 2008), could be a new expanding 'global market for IUCN Red List categories and criteria' that strengthens the data on the world's threatened species.

\section{NRLTS and SRLTS coverage}

Some taxa, such as non-vascular plants and most invertebrates, were underrepresented in NRLTSs and SRLTSs (Köppel et al. 2003, Zamin et al. 2010), leading to a corresponding bias in conservation policies (Mace et al. 2008, Martín-López et al. 2011). While the focus is on species for which data is available, the lack of currently available data may conceal greater threats to other species (McKinney 1999). The same pattern can be observed at European and global levels (Miller 2013). However, it is encouraging that interest in developing RLTSs for under-represented groups of invertebrates has shown some signs of increasing in recent years. In 2008, Zamin et al. (2010) estimated that $53 \%$ of NRLTSs worldwide assessed at least one invertebrate taxon. The present study shows that $85 \%$ of Euro-Mediterranean NRLTSs contained assessments for invertebrates, although the majority concerned the most well-known taxa: Lepidoptera and odonates. However, it should be noted that this current state of taxa included in NRLTSs and SRLTSs is not a quantitative evaluation of the species assessed per country, as the survey did not ask for information on the number of species assessed.

We also identified a gap in RLTS coverage in most eastern and southern Mediterranean countries (Balmford et al. 2005, Green et al. 2005, Zamin et al. 2010). Most of these countries are part of the Mediterranean biome, which is recognized as a hotspot of biodiversity (Myers et al. 2000) and as being exposed to a high level of threat (Cuttelod et al. 2009). Zamin et al. (2010) attributed this gap in RLTS coverage to the lack of funding; however, our study downplays this hypothesis. Countries that did not plan to develop an NRLTS did not identify financial constraints as the primary obstacle, and funding availability was not a determining factor in their choice of which taxonomic groups to assess. Moreover, neither Gross Domestic Product (GDP; The World Bank 2013), nor a potential threshold GDP effect, was identified as a significant variable influencing a country's conservation strategy in the PCA analysis (Fig. S3 in Supplement 3). Instead, availability of data and expertise was identified as the major factor determining development of NRLTSs. Rather, lack of expert knowledge was identified as the principal constraint to RLTSs in these countries. Our study therefore confirms the essential role of experts for biodiversity knowledge and conservation (Miller et al. 2007, Coreau 2014, Hjarding et al. 2015). Respondents highlighted the need for the training of conservation experts, along with structured support from political decision makers and international organizations for the production of NRLTSs. In this regard, the elaboration of the Mediterranean RLTS could function as a structuring 
initiative to build capacity at national and subnational levels. It can also help towards harmonizing data quality and assessment processes around the Mediterranean basin. This initiative should include increasing the mobilization and training of conservation stakeholders, especially from scientific and political sectors.

\section{Role of RLTSs in biodiversity conservation programs and policies}

Our review of biodiversity conservation programs and policies in the Euro-Mediterranean countries did not aim to be exhaustive but instead to give an overview of the conservation framework in the region. The review documents a 'north-south' divide in conservation programs, and a stronger development of programs linked to international commitments compared to locally based initiatives. The survey shows that the European Union, and especially its Birds and Habitats Directives, has been a driving force to strengthen conservation strategies in the member countries. Species diversity knowledge and data collection are stimulated by the Habitat Directive progress reports and the development of protected areas (and green corridors) by the Natura 2000 network. Some countries adopted the species listed in the annexes of the Directives as a national list of regulated and protected species without any modification. However, conservation priorities at the European level are not always representative of local priorities, and stakeholders need access to locally adapted tools to design conservation strategies. In the context of a much needed harmonization of European strategies to increase the efficiency of conservation efforts (Bladt et al. 2009), NRLTSs and SRLTSs, in combination with European RLTS assessments, could be valuable tools to design standardized but adaptive programs at the EU scale.

This first international assessment of RLTS use in national conservation strategies shows they are actively used in at least two-thirds of the national programs of the surveyed countries. NRLTSs are the primary RLTSs used, while SRLTSs are more frequently used for small-scale programs. This strong and targeted use of NRLTSs and SRLTSs clearly justifies the multi-scale human and financial investment in RLTSs. Though the European RLTS is a valuable tool, subnational and national actors prefer using a scale-adapted tool that meets their specific requirements. The study also confirms the uses of RLTSs in determining species conservation priori- ties, for information and communication, advice for policies and programs, monitoring of the state of biodiversity, and orientation for research, as outlined by previous work (Lamoreux et al. 2003, Rodrigues et al. 2006). No further major uses of RLTSs were identified by this study in responses to the open questions. National and subnational actors mainly use RLTSs for prioritizing species for protection. Nevertheless, a confusion persists between risk of extinction and conservation priorities or rarity (Miller et al. 2007, Fitzpatrick et al. 2007, Mace et al. 2008) that can affect RLTS efficiency and constrain support from policymakers (Possingham et al. 2002, Lamoreux et al. 2003). As a prioritization tool, RLTSs must be associated with other factors such as national responsibility and opportunities for action (Keller \& Bollmann 2004, Rodríguez et al. 2004, Schatz et al. 2014, Schmeller et al. 2014). The combination of multi-scale RLTSs (including available assessments from the global, regional, national and subnational RLTSs) can also provide valuable information during prioritization processes (Barneix \& Gigot 2013). The combination of RLTSs with other knowledge products such as the Red List of Ecosystems (Keith et al. 2013) and Key Biodiversity Areas (Foster et al. 2012) also provides great potential for enhanced conservation planning.

The various strategies employed in producing NRLTSs highlight the differences in the way NRLTSs are used. For example, France has assessed most well-known groups following the 2001 IUCN methodology and with the support of the IUCN national committee (UICN France \& MNHN 2009). The NRLTS is one of the major prioritization tools used in most of the national conservation programs in France. In contrast, the United Kingdom has mainly assessed less well-known groups (JNCC 2014) using the 2001 IUCN methodology complemented with national criteria. Other taxa are assessed through other tools, for example the programme Tracking Mammals Partnership developed by the JNCC (JNCC 2005). This indicates a different ownership of the tool as well as different needs between countries.

\section{Strengthening NRLTS and SRLTS consistency through improved coordination}

NRLTSs and SRLTSs are elaborated following different methodological guidelines, which complicates the use of RLTSs at other scales. Answers from respondents showed that this is particularly problematic for SRLTSs that can rarely be combined for use in 
national programs. However, using multi-level RLTSs is a benefit to conservation as it facilitates the multiscale mapping of threats (Brito et al. 2010). To fully realize this potential, RLTSs must be consistent across scales and follow a similar methodological approach. Consistent RLTSs could, among other things, provide the global RLTS with valuable information from NRLTS and SRLTS assessments, especially for endemic species, and support cross-border cooperation for conservation (Rodríguez 2008). This would improve the role of RLTSs as 'barometers of life' (Stuart et al. 2010).

To strengthen RLTS consistency, communication must be improved among RLTS producers (Miller et al. 2007). Meetings like the European seminar on the harmonization of NRLTSs in Europe in 2002 (De Iongh et al. 2003) are excellent initiatives but they should be scheduled on a more regular basis. Strengthening the NRLTS and SRLTS network would allow sharing of experience to facilitate the application of IUCN methodology, especially for less wellknown species or undocumented areas.

The NRLA has been set up with this objective but it needs to strengthen its role as a link between RLTS actors. The nationalredlist.org website could provide good support but it would need regular updates as well as a section for RLTS users to exchange information on RLTS uses and prioritization processes. This network strengthening would be the next step for NRLTSs and SRLTSs toward becoming a key tool for inter-regional and trans-boundary cooperation for species conservation (Kark et al. 2009). A worldwide strategy is needed to fill the gaps in NRLTS and SRLTS coverage through funding and knowledge transfer initiatives. Such a strategy has to include an RLTS quality control process to harmonize development of RLTS and increase linkages between the multiple levels of RLTSs.

\section{CONCLUSION}

National and subnational RLTSs have come a long way. RLTSs are now a valuable reference tool for conservationists, who have access to global, regional, national and subnational assessments to plan their conservation actions. This study confirms previous findings (Köppel et al. 2003, Miller et al. 2007, Rodríguez 2008, Zamin et al. 2010) and provides an updated and more detailed view on NRLTSs and SRLTSs. For the first time, specific information on SRLTS development and the use of RLTSs in national conservation programs is made available, which we hope will help conservationists and decision makers during conservation and policy planning. Though comparative research on RLTSs in other geographical regions is needed, this overview for the EuroMediterranean region provides us with some interesting insights. Three main actions are needed to address the unequal development and use of NRLTSs and SRLTSs:

(1) Improved training should be provided and increased resources made available to experts on a worldwide scale. This is the key to increasing the data on underrepresented taxa and geographical areas. The IUCN could then develop specific guidance and stimulate specialist working groups (e.g. for invertebrates; Proctor \& Harding 2005, Cardoso et al. 2011).

(2) The IUCN should provide more widely available guidelines on the application of IUCN methodology, especially for less well-known taxonomic groups (IUCN 2014a), and the appropriate use of RLTSs for conservation (IUCN 2011). Following the increasing interest in SRLTSs, specific recommendations for SRLTS actors must be drafted. For example, the national IUCN committee in France, in collaboration with local partners, is in the process of producing guidelines on the development and use of SRLTSs (UICN France 2011). However, we remind local actors that a considerable amount of information is already available on the website (www.iucnredlist.org) as well as RLTS training on www.conservationtraining.org (The Nature Conservancy 2014).

(3) Increased coordination between RLTS stakeholders at all scales (from global to subnational) is required. The NRLA needs more support from the international community to fulfill its coordinating and support function efficiently as well as maintaining an updated website (www.nationalredlist.org). However, in the context of limited resources, national and subnational actors also have their parts to play. We strongly encourage these actors to contact the NRLA acting at a larger scale and those in neighboring countries/regions to share experiences and pool efforts towards a better assessment and conservation of species. This will enable local actors to get the best value from their strong investments in RLTSs.

Acknowledgements. We thank all individuals across EuroMediterranean countries who helped us gather this information and especially those who answered the questionnaire. For their contributions in this study, we also thank L. Billon, P. Dupont, P. Haffner, A. Horellou, A. Savouret Soubelet, R. Sordello and J. Touroult (Service du Patrimoine NaturelMuséum National d'Histoire Naturelle, SPN-MNHN), A. Carvois and F. Kirshner (UICN France), S. Bachman (Royal 
Botanic Gardens, Kew), A. Nieto (IUCN Europe), D. Allen, A. Cuttelod and C. Hilton Taylor (IUCN Species Programme), M. Böhm and A. Saltmarsh (Zoological Society of London), A. Rodrigues and J. Thompson (Centre d'Ecologie Fonctionnelle et Evolutive, CEFE), E. Vela (Centre de coopération internationale en recherche agronomique pour le développement, CIRAD), A. Coreau and S. Rabaud (AgroParitech), A. Cluchier (ECO-MED) and S. Condé (European Topic Centre on Biological Diversity). We also thank the anonymous reviewers for their valuable advice. The protocols of this study were approved by the board of directors of the SPN-MNHM (Paris).

\section{LITERATURE CITED}

ARCGIS (2014) ArcGIS. www.arcgis.com/features/ (accessed 3 Dec 2014)

Balmford A, Crane P, Dobson A, Green RE, Mace GM (2005) The 2010 challenge: data availability, information needs and extraterrestrial insights. Philos Trans R Soc Lond B Biol Sci 360:221-228

Barneix M, Gigot G (2013) Listes rouges des espèces menacées et enjeux de conservation: étude prospective pour la valorisation des listes rouges régionales - propositions méthodologiques. Service du Patrimoine NaturelMuséum national d'Histoire naturelle (SPN-MNHN), Paris

Barnosky AD, Matzke N, Tomiya S, Wogan GO and others (2011) Has the Earth's sixth mass extinction already arrived? Nature 471:51-57

BFN (2014) BFN: Red List publications (in German). www.bfn.de/0322_veroe+M5054de7a952.html (accessed 15 Mar 2015)

Bladt J, Strange N, Abildtrup J, Svenning JC, Skov F (2009) Conservation efficiency of geopolitical coordination in the EU. J Nat Conserv 17:72-86

Blondel J, Aronson J, Bodiou JY, Boeuf G (2010) The Mediterranean region: biological diversity through time and space. Oxford University Press, Oxford

Brito D, Ambal RG, Brooks T, Silva ND and others (2010) How similar are national red lists and the IUCN Red List? Biol Conserv 143:1154-1158

Burton JA (2003) The context of Red Data Books, with a complete bibliography of the IUCN publications. In: de Iongh $\mathrm{HH}$, Bánki OS, Bergmans W, van der Werff ten Bosch MJ (eds) The harmonization of Red Lists for threatened species in Europe. The Netherlands Commission for International Protection, Leiden, p 291-300

Butchart SHM, Stattersfield AJ, Baillie J, Bennun LA and others (2005) Using Red List Indices to measure progress towards the 2010 target and beyond. Philos Trans R Soc Lond B Biol Sci 360:255-268

Butchart SH, Walpole M, Collen B, Van Strien A and others (2010) Global biodiversity: indicators of recent declines. Science 328:1164-1168

Cardoso P, Borges PAV, Triantis KA, Ferrández MA, Martín JL (2011) Adapting the IUCN Red List criteria for invertebrates. Biol Conserv 144:2432-2440

Carvalheiro LG, Kunin WE, Keil P, Aguirre-Gutiérrez J and others (2013) Species richness declines and biotic homogenization have slowed down for NW-European pollinators and plants. Ecol Lett 16:870-878

CBD (Convention on Biodiversity) (2014) Decisions adopted by the conference of the parties at its twelfth meeting.
Pyeongchang, South Korea. www.cbd.int/doc/decisions/ cop-12/full/cop-12-dec-en.pdf

Coface (2014) Economic studies. www.coface.com/EconomicStudies-and-Country-Risks (accessed 5 Aug 2014)

Cog lniceanu D, Cog lniceanu GC (2010) An enlarged European Union challenges priority settings in conservation. Biodivers Conserv 19:1471-1483

Collen B, Griffiths J, Friedmann Y, Rodríguez JP, RojasSuárez F, Baillie JEM (2013) Tracking change in national-level conservation status: National Red Lists. In: Collen B, Pettorelli N, M. Baillie JEM, Durant SM (eds) Biodiversity monitoring and conservation: bridging the gap between global commitment and local action. John Wiley and Sons, Hoboken, NJ, p 19-44

Coreau A (2014) Les stratégies d'expertise des écologues. Regards 58, Société Française d'Ecologie. www.sfeco logie.org/regard/r58-experts-a-coreau/

Council of the European Commission (1992) Council directive 92/43/EEC of 21 May 1992 on the conservation of natural habitats and of wild fauna and flora. Off J Eur Union L 206:7-49

Council of the European Commission (2009) Directive 2009/147/EC of the European parliament and of the Council of 30 November 2009 on the conservation of wild birds (codified version). Off J Eur Union L 20:7-25

Cuttelod A, García N, Malak DA, Temple HJ, Katariya V (2009) The Mediterranean: a biodiversity hotspot under threat. In: Vié JC, Hilton-Taylor C, Stuart SN (eds) The 2008 review of the IUCN Red List of Threatened Species. IUCN, Gland

De Grammont PC, Cuarón AD (2006) An evaluation of threatened species categorization systems used on the American continent. Conserv Biol 20:14-27

De Iongh HH, Bánki OS, Bergmans W, Van der Werff ten Bosch MJ (2003) The harmonization of Red Lists for threatened species in Europe. Proceedings of an International Seminar in Leiden, 27 and 28 November 2002. Mededelingen No. 38, The Netherlands Commission for International Nature Protection, Leiden

> Farrier D, Whelan R, Mooney C (2007) Threatened species listing as a trigger for conservation action. Environ Sci Policy 10:219-229

> Fitzpatrick Ú, Murray TE, Paxton RJ, Brown MJF (2007) Building on IUCN Regional Red Lists to produce lists of species of conservation priority: a model with Irish bees. Conserv Biol 21:1324-1332

Foster MN, Brooks TM, Cuttelod A, De Silva N, Fishpool LDC, Radford EA, Woodley S (2012) The identification of sites of biodiversity conservation significance: progress with the application of a global standard. Journal of Threatened Taxa 4:2733-2744

GADM (2014) Global administrative areas: boundaries without limits. http://gadm.org/ (accessed 15 Jul 2014)

Gärdenfors U (2001) Classifying threatened species at national versus global levels. Trends Ecol Evol 16: 511-516

Green RE, Balmford A, Crane PR, Mace GM, Reynolds JD, Turner RK (2005) A framework for improved monitoring of biodiversity: responses to the World Summit on Sustainable Development. Conserv Biol 19:56-65

> Henle K, Bauch B, Auliya M, Külvik M, Pe'er G, Schmeller DS, Framstad E (2013) Priorities for biodiversity monitoring in Europe: a review of supranational policies and a novel scheme for integrative prioritization. Ecol Indic 33: 5-18 
Hjarding A, Tolley KA, Burgess ND (2015) Red List assessments of East African chameleons: a case study of why we need experts. Oryx 49:652-658

IUCN (1994) IUCN Red List categories. IUCN Species Survival Commission, IUCN, Gland

IUCN (2001) IUCN Red List categories and criteria, Version 3.1. Species Survival Commission, IUCN, Gland

IUCN (2003) Guidelines for application of IUCN Red List criteria at regional and national levels. IUCN, Gland

IUCN (2011) Guidelines for appropriate uses of IUCN Red List data. Incorporating the guidelines for reporting on proportion threatened and the guidelines on scientific collecting of threatened species. Version 2. Adopted by the IUCN Red List Committee and IUCN SSC Steering Committee. IUCN, Gland

IUCN (2012a) IUCN Red List categories and criteria, Version 3.1, 2nd edn. IUCN, Gland

IUCN (2012b) Guidelines for application of IUCN Red List criteria at regional and national levels, Version 4.0. IUCN, Gland

IUCN (2014a) Guidelines for using the IUCN Red List categories and criteria, Version 11. Standards and Petitions Subcommittee, IUCN, Gland

IUCN (2014b) The IUCN Red List of Threatened Species, Version 2014. 2. www.iucnredlist.org (accessed 5 Mar 2014)

JNCC (Joint Nature Conservation Committee) (2005) UK mammals species status and population trends. http:// jncc.defra.gov.uk/page-3311 (accessed 15 Dec 2014)

JNCC (2014) Species status assessment. http://jncc.defra. gov.uk/page-1773 (accessed 15 Dec 2014)

Kark S, Levin N, Grantham HS, Possingham HP (2009) Between-country collaboration and consideration of costs increase conservation planning efficiency in the Mediterranean Basin. Proc Natl Acad Sci USA 106: 15368-15373

Keith DA, Rodríguez JP, Rodríguez-Clark KM, Nicholson E and others (2013) Scientific foundations for an IUCN Red List of Ecosystems. PLoS One 8:e62111

Keller V, Bollmann K (2004) From Red Lists to species of conservation concern. Conserv Biol 18:1636-1644

Köppel C, Jansen F, Burton J, Schnittler M, Hirneisen N (2003) A statistical survey on European Red Lists. In: de Iongh $\mathrm{HH}$ et al. (eds) The harmonization of Red Lists for threatened species. Proceedings of an International Seminar in Leiden, 27 and 28 November 2002. Mededelingen No. 38, The Netherlands Commission for International Nature Protection, Leiden, p 59-75

Lamoreux J, Akçakaya HR, Bennun L, Collar NJ and others (2003) Value of the IUCN Red List. Trends Ecol Evol 18: 214-215

LimeSurvey (2011) LimeSurvey - the free and open source survey software tool. www.limesurvey.org (accessed 15 Mar 2014)

- Mace GM, Lande R (1991) Assessing extinction threats: toward a reevaluation of IUCN threatened species categories. Conserv Biol 5:148-157

Mace GM, Collar NJ, Gaston KJ, Hilton-Taylor C and others (2008) Quantification of extinction risk: IUCN's system for classifying threatened species. Conserv Biol 22:1424-1442

Martín-López B, González JA, Montes C (2011) The pitfalltrap of species conservation priority setting. Biodivers Conserv 20:663-682
McKinney ML (1999) High rates of extinction and threat in poorly studied taxa. Conserv Biol 13:1273-1281

Miller RM (2013) Threatened species: classification systems and their applications. In: Levin SA (ed) Encyclopedia of biodiversity, 2nd edn, Vol 7. Academic Press, Waltham, MA, p 191-211

Miller RM, Rodriguez JP, Aniskowicz-Fowler T, Bambaradeniya $C$ and others (2007) National threatened species listing based on IUCN criteria and regional guidelines: current status and future perspectives. Conserv Biol 21: 684-696

- Myers N, Mittermeier RA, Mittermeier CG, da Fonseca GAB, Kent J (2000) Biodiversity hotspots for conservation priorities. Nature 403:853-858

National Red List (2014) National red list. www.national redlist.org (accessed 5 Mar 2014)

> Pereira HM, Leadley PW, Proença V, Alkemade R and others (2010) Scenarios for global biodiversity in the 21st century. Science 330:1496-1501

> Possingham HP, Andelman SJ, Burgman MA, Medellín RA, Master LL, Keith DA (2002) Limits to the use of threatened species lists. Trends Ecol Evol 17:503-507

Proctor D, Harding PT (2005) Proceedings of INCardiff 2003 Red lists for invertebrates. Report 367, Joint Nature Conservancy Committee, Peterborough

Rodrigues ASL, Pilgrim J, Lamoreux J, Hoffmann M, Brooks $\mathrm{T}$ (2006) The value of the IUCN Red List for conservation. Trends Ecol Evol 21:71-76

Rodríguez JP (2008) National Red Lists: the largest global market for IUCN Red List categories and criteria. Endang Species Res 6:193-198

Rodríguez JP, Rojas-Suárez F, Sharpe CJ (2004) Setting priorities for the conservation of Venezuela's threatened birds. Oryx 38:373-382

Schatz B, Gauthier P, Debussche M, Thompson JD (2014) A decision tool for listing species for protection on different geographic scales and administrative levels. J Nat Conserv 22:75-83

Schmeller DS, Evans D, Lin YP, Henle K (2014) The national responsibility approach to setting conservation priorities-recommendations for its use. J Nat Conserv 22: 349-357

> Stuart SN, Wilson EO, Mc Neely JA, Mittermeier RA, Rodriguez JP (2010) The barometer of life. Science 328: 177

The Nature Conservancy (2014) Conservation training. www.conservationtraining.org (accessed 15 Mar 2015)

The World Bank (2013) Data. http://data.worldbank.org/ (accessed 18 Aug 2014)

UICN France, MNHN (Muséum national d'histoire naturelle) (2009) La liste rouge des espèces menacées en France: contexte, enjeux et démarche d'élaboration. Comité français de l'UICN, Paris

UICN France (2011) Guide pratique pour la réalisation de listes rouges régionales des espèces menacées: méthodologie de l'UICN et démarche d'élaboration. Comité français de l'UICN, Paris

UNEP (2014) Convention on Biological Diversity. www. cbd.int (accessed 14 Mar 2014)

- Zamin TJ, Baillie JEM, Miller RM, Rodríguez JP, Ardid A, Collen B (2010) National red listing beyond the 2010 target: addressing national Red-List gaps. Conserv Biol 24:1012-1020

Submitted: July 7, 2015; Accepted: May 10, 2016

Proofs received from author(s): July 17, 2016 